\title{
Effectiveness and safety of dinoprostona and cook's balloon for labour induction in pregnants with small for gestational age fetuses
}

\begin{abstract}
Summary
Objectives: To compare the effectiveness (hours until delivery) and safety (rate of vaginal deliveries and caesarean sections, use of oxytocin and perinatal outcomes) of dinoprostone and Cook's balloon as a method of labor induction in pregnant women with fetuses with an estimated weight below the 10th percentile and normal Doppler.

Methods: retrospective cohort review of pregnant women with small for gestational age fetuses and induced with both methods in Reina Sofía Hospital, Cordoba, Spain from 2014 to 2018. The main outcome was time until delivery. Descriptive characteristics, obstetric and perinatal outcomes were analyzed. 322 pregnant women were induced: 204 women were induced with Cook's balloon $(\mathrm{CB})$ and 118 with dinoprostone (DIN). RESULTS: Dinoprostone decreases the time until delivery (28.86 vs. 24.32 hours with CB and DIN, respectively, $\mathrm{p}<0.0001)$ and the use of oxytocin $(79.7 \%$ vs $54.2 \%$ in CB and DIN group; $\mathrm{p}<0,01$ ), as compared to Cook's balloon. No differences were observed in the rate of caesarean sections and vaginal deliveries, as well as in perinatal results.
\end{abstract}

Conclusion: DIN reduces the time to delivery compared to $\mathrm{CB}$ with a lower need for oxytocin. Moreover, without worse perinatal outcomes.

Keywords: induction of labor, dinoprostone, doble ballon, cook's balloon
Volume II Issue 4 - 2020

\author{
Porras Lucena Marta,Vendrell Aranda Celia \\ María, Duro Gómez Jorge \\ Gynecology and Obstetrics, Universita ry Hospital Reina Sofía \\ Córdoba, Spain
}

\begin{abstract}
Correspondence: Jorge Duro Gómez, Gynecology and Obstetrics, Universita ry Hospital Reina Sofía Córdoba, C/Arabista Joaquina Eguaras N ${ }^{\circ} 2 \mathrm{ESC} 4 \mathrm{I}^{\circ} \mathrm{B}, \mathrm{CP}$ I40 I I CÓRDOBA, Spain, Tel +34685810803,

Email jorgedurogomez@gmail.co
\end{abstract}

Received: May 3I, 2020 | Published: July 202020

\section{Introduction}

Labor induction is an obstetric procedure whose purpose is to cause uterine contractions to trigger labor. It can be carried out by pharmacological and/or mechanical methods, depending on the characteristics of the pregnant woman and the obstetric condition. Cook's balloon is a mechanical method, it alters amnion-chorion integrity, stimulates collagen and causes release of endogenous prostaglandins in uterine cervix. ${ }^{1}$

Dinoprostone is an analog of prostaglandin E2 (PGE2), it causes cervical ripening similar to endogenous ripening with spontaneous labor. $^{2}$

Recommended standard of inductions by World Health Organization (WHO) is less than $10 \%$ of deliveries; however, this number is increasing: $19.4 \%$ of deliveries were induced according to data provided in $2012^{3}$ by the Spanish Ministry of Health.

The main outcome is to compare effectiveness (hours until delivery) of Cook's Ballon (Cook Cervical Ripening Balloon ${ }^{\circledR}$, Cook Incorporated, IN, USA) against dinoprostone $10 \mathrm{mg}$ (Propess ${ }^{\circledR}$, Ferring Pharmaceutical, Saint-Prex, Switzerland), as a method of induction in women with fetuses with an estimated fetal weigh below the $10^{\text {th }}$ percentile and normal Doppler. We also include secondary outcome with regard to safety of induction: rate of vaginal deliveries and caesarean sections, use of oxytocin and perinatal outcomes.

\section{Methods}

We have performed a retrospective cohort study. 322 pregnant women were recruited consecutively from 2014 to 2018 at Reina Sofia Hospital, Córdoba.
204 were induced with $\mathrm{CB}$ and 118 patients were induced with DIN. Inclusion criteria were pregnant women with fetuses with an estimated fetal weight below the $10^{\text {th }}$ percentile and normal Doppler, and Bishop $<7$. Women with contraindication to vaginal delivery and multiple gestation were excluded.

In $\mathrm{CB}$ group, balloon was manually inserted into the cervix, and intrauterine and intravaginal balloons were filled with $50 \mathrm{ml}$ of saline. In DIN group, a $10 \mathrm{mg}$ device was insert into the posterior vaginal fornix for $24 \mathrm{~h}$.

In both cases, a cardiotocographic monitoring was performed for $30 \mathrm{~min}$ and repeated every 6 hours. If after 24 hours, active phase of labor had not been achieved ( $3 \mathrm{~cm}$ dilatation and 3-4 contractions every 10 minutes), artificial amniorrexis and oxytocin infusion was added. In case of polysystolia or nonreassuring fetal status, both devices were removed.

According to previous studies, the variables included for analysis were time to delivery (hours), age (years), Bishop, birth weight, parity, mode of delivery, use of oxytocin (IU), umbilical artery pH, APGAR score at 1 and 5 minutes, admission to Neonatal Intensive Care Unit (NICU).

Accepting an alpha risk of 0.05 and a beta risk of 0.2 in a bilateral contrast at least 110 subjects in the one group and 44 in the other group are required to detect a difference equal to or greater than 3 hours. A follow-up loss rate of $0 \%$ has been estimated.

Statistical analysis was performed with SPSS v25 software (IBM® SPSS ${ }^{\circledR}$ Statistics, 2019). Chi-square test was used for assessing statistical significance for qualitative variables, and Student's t test was used for quantitative variables. A value of $\mathrm{p}<0,05$ was considered statistically significant. 


\section{Results}

No significant differences were observed in age, parity, Bishop Score and gestational age. Differences were statistically significant when studying birth weight (2295.58 $\mathrm{g}$ in CB group compared to 2406.27g in DIN group, $\mathrm{p}$ 0.004) (Table 1).

Table I Baseline characteristics of pregnant women with SGA. CB: Cook's ball. DIN: dinoprostone

\begin{tabular}{|c|c|c|c|}
\hline & $\begin{array}{l}\text { CB GROUP } \\
(\mathrm{N}=204)\end{array}$ & $\begin{array}{l}\text { DIN GROUP } \\
(N=|| 8)\end{array}$ & $P$ value \\
\hline Age (years) & $29,73(5,934)$ & $30,79(6,537)$ & 0,139 \\
\hline Parity & 0,5 I $(0,79 \mid)$ & $0,65(0,890)$ & 0,137 \\
\hline Bishop score & $2,20(1,098)$ & $2,10(1,343)$ & 0,503 \\
\hline $\begin{array}{l}\text { Gestational age } \\
\text { (weeks) }\end{array}$ & $37,96(1,521)$ & $38,29(2,013)$ & 0,127 \\
\hline $\begin{array}{l}\text { Birth weight } \\
\text { (grams) }\end{array}$ & $2295,58(310,472)$ & $\begin{array}{l}2406,27 \\
(355,574)\end{array}$ & 0,004 \\
\hline
\end{tabular}

DIN reduced the time until delivery statistically significantly, as compared to BC (28.86 hours vs. 24.32 hours with CB and DIN, respectively, $\mathrm{p}<0.0001$ ) (Figure 1).

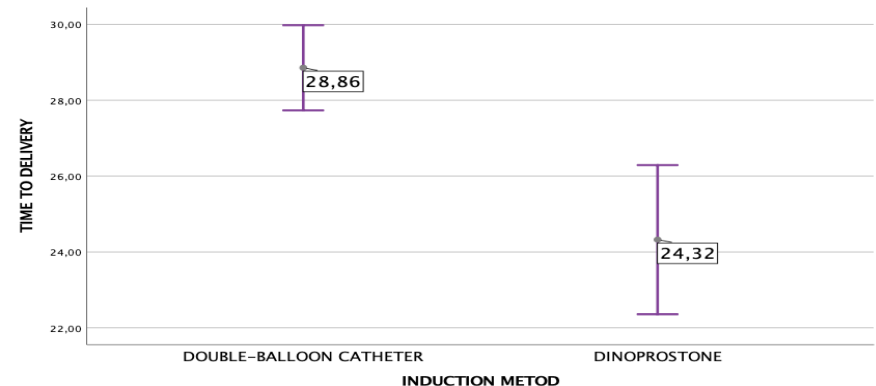

Figure I Analysis of the time until vaginal delivery in both treatment groups (hours).

The rate of vaginal deliveries and caesarean sections was similar in both groups. However, significant differences were observed in the use of oxytocin: a higher use was required in the BC than in the DIN group. (79.7\% vs $54.2 \%$ in $\mathrm{CB}$ and DIN group, respectively; $\mathrm{p}<0$, 01) (Table 2).

Table 2 Analysis of mode of delivery and use of oxytocin. CB: Cook's ball. DIN: dinoprostone

\begin{tabular}{llll}
\hline & $\begin{array}{l}\text { CB GROUP } \\
(\mathbf{N}=204)\end{array}$ & $\begin{array}{l}\text { DIN GROUP } \\
(\mathbf{N}=1 \text { I 8) }\end{array}$ & P value \\
\hline Mode of delivery & & & \\
- normal & $142(69,9 \%)$ & $82(69,5 \%)$ & 1,000 \\
- operative & $12(5,9 \%)$ & $7(5,9 \%)$ & \\
- Caesarean & $50(24,5 \%)$ & $29(24,6 \%)$ & \\
Use of oxytocin & $161(79,7 \%)$ & $64(54,2 \%)$ & $<0,0 \mathrm{I}$ \\
\hline
\end{tabular}

Finally, we evaluated perinatal outcomes. APGAR score at one and five minutes after birth, umbilical artery $\mathrm{pH}$, and admission to the NICU were similar in both groups, without finding statistically significant differences (Table 3 ).
Table 3 Perinatal outcomes. CB: Cook's ball. DIN: dinoprostone

\begin{tabular}{llll} 
& $\begin{array}{l}\text { CB GROUP } \\
(\mathbf{N}=\mathbf{2 0 4})\end{array}$ & $\begin{array}{l}\text { DIN GROUP } \\
(\mathbf{N}=\mathbf{I} \text { I 8) }\end{array}$ & P value \\
\hline I-min Apgar & $8,70(0,906)$ & $8,64(0,967)$ & 0,543 \\
5-min Apgar & $9,96(2,172)$ & $9,77(0,546)$ & 0,353 \\
Umbilical artery pH & $7,28(0,08232)$ & $7,19(0,68281)$ & 0,180 \\
NICU admission & $63(30,88 \%)$ & $25(21,18 \%)$ & 0,080 \\
\hline
\end{tabular}

\section{Discussion}

The rate of induced births has been increasing exponentially in recent years, making it a very important procedure in daily obstetric practice.

Our work includes a total of 322 patients, 204 in the Cook ballooninduced group of pregnant women and 118 in the dinoprostone group. At first, in our Hospital, only the DIN was used, but CB replaced it when it was introduced. Therefore, the CB group is more numerous.

In our opinion, reducing the time required for vaginal delivery improves the satisfaction of the patients, as long as it does not affect maternal and fetal well-being. In our work, pregnant women induced with DIN achieved vaginal delivery in a significantly shorter period of time than pregnant women induced with CB. However, the results are heterogeneous among the studies analyzed; Du et al. ${ }^{4}$, Cromi et al. ${ }^{5}$ and Brown et $\mathrm{l}^{6}$ found no differences in time to delivery, although in the clinical trial by Suffecool et al. ${ }^{7}$ they observed a shorter time to delivery in the case of $\mathrm{BC}$. These differences may be due to the different protocols used in each center and the heterogeneity between studies.

According to other studies that perform a similar analysis, ${ }^{4,5,7-10}$ we have not observed statistically significant differences regarding the type of delivery in the two groups compared.

As we can see in the meta-analysis by Du et al., ${ }^{4}$ it seems a lower need for oxytocin in the group of pregnant women induced with DIN . In our case, we might think that this finding is related to the shortest time necessary to achieve labor with this method; by decreasing the time until delivery, we decrease the need to use oxytocin. Another reason could be to achieve greater intensity and frequency of uterine dynamics with DIN. However, this is a retrospective study and, as well as the presence of tacysystole, we do not have the necessary data to analyze this fact.

According to Duro et $\mathrm{al}^{8}{ }^{8}$ and Løkkegaard et al. ${ }^{9}$ i, perinatal outcomes are similar in both groups. However, Du et al. ${ }^{4}$ observed a higher NICU admission rate and a worse umbilical cord $\mathrm{pH}$ in induction of labor with dinoprostone. Brown et al. ${ }^{6}$ also noted worse $\mathrm{pH}$ results in the dinoprostpme induced group, but without increasing the rate of admission. Although not significantly, we observed in our study a higher NICU admission rate in the group of pregnant women induced with $\mathrm{CB}$, probably related to the lower weight of the neonates.

Liu et al. ${ }^{10}$ did not observe a significant decrease in the time until vaginal delivery in a meta-analysis of randomized studies. Nevertheless, there was less need for oxytocin in the DIN group. However, in this case it assumed a lower neonatal $\mathrm{pH}$ value, which we have not observed in our work. 
We must take into account the limitations of work. Firstly, it is a retrospective study and some variables as tachysystole are not evaluated. For this reason, we have ignored their comparaison. Moreover, there is no randomization, which means that the groups are not homogeneous, and the sample is larger in one group than in another. Therefore, we believe that it can serve as a basis for other future prospective and randomized studies to more reliably verify our results. Finally, fetal weight was lower in the $\mathrm{CB}$ group. We consider that it is a fact that must be taken into account when analyzing our results.

\section{Conclusion}

Dinoprostone reduces the time to delivery compared to double balloon with a lower need for oxytocin. Moreover, without worse perinatal outcomes.

\section{Acknowledgments}

None.

\section{Funding}

None.

\section{Conflicts of interest}

The authors declare no conflict of interest. No external financing has been used.

\section{References}

1. De Bonrostro Torralba C, Tejero Cabrejas EL, Marti Gamboa S, et al. Double-balloon catheter for induction of labour in women with a previous cesarean section, could it be the best choice? Arch Gynecol Obstet. 2017;295(5):1135-1143.
2. Pierce S, Bakker R, Myers DA, et al. Clinical Insights for cervical ripening and labor induction using prostaglandins. AJP reports. 2018;8(4):e307-e314.

3. Ministerio de sanidad, consumo y bienestar social. Madrid: Ministerio desanidad, consumo y bienestar social. 2012.

4. Du YM, Zhu LY, Cui LN, et al. Double-balloon catheter versus prostaglandin E2 for cervical ripening and labour induction: a systematic review and meta-analysis of randomised controlled trials. BJOG. 2017;124(6):891-899.

5. Cromi A, Ghezzi F, Uccella S, et al. A randomized trial of preinduction cervical ripening: dinoprostone vaginal insert versus double-balloon catheter. Am J Obstet Gynecol. 2012;207(2):125-127.

6. Brown J, Beckmann M. Induction of labour using balloon catheter and prostaglandin gel. Aust N Z J Obstet Gynaecol. 2017;57(1):68-73.

7. Suffecool K, Rosenn BM, Kam S, et al. Labor induction in nulliparous women with an unfavorable cervix: double balloon catheter versus dinoprostone. J Perinat Med. 2014;42(2):213-218.

8. Duro Gómez J, Garrido-Oyarzún MF, Rodríguez Marín AB, et al. Efficacy and safety of misoprostol, dinoprostone and Cook's balloon for labour induction in women with foetal growth restriction at term. Arch Gynecol Obstet. 2017;296:777-781.

9. Løkkegaard E, Lundstrøm M, Kjær MM, et al. Prospective multi-centre randomised trial comparing induction of labour with a double-balloon catheter versus dinoprostone. J Obstet Gynaecol. 2015;35(8):797-802.

10. Liu YR, Pu CX, Wang XY, et al. Double-balloon catheter versus dinoprostone insert for labour induction: a meta-analysis. Arch Gynecol Obstet. 2019;299(1):7-12. 